\title{
Seismic assessment of a historical masonry arch bridge
}

\author{
A. Özmen ${ }^{1}$, E. Sayın ${ }^{2 *}$ \\ ${ }^{1}$ Inonu University, Department of Civil Engineering, 44000, Malatya, Turkey \\ ${ }^{2}$ Firat University, Department of Civil Engineering, 23119, Elazı̆̆, Turkey
}

\begin{abstract}
Historical masonry arch bridges which are important components of the transportation in many places worldwide are invaluable part of architectural and cultural heritage. These bridges, which date back to hundreds of years, have frequently been damaged or ruined because of unexpected events such as earthquakes. In this study, earthquake behaviour of a historical masonry arch bridge which called Dutpinar is analysed using 2003 Bingöl earthquake acceleration records. The bridge is modelled with three dimensional finite element software. Dynamic response of the bridge is investigated. For this purpose, displacement of the nodal point located at the top of the bridge is achieved. Also, maximum and minimum principal stress and strains are obtained and potential locations of initial damages are evaluated.
\end{abstract}

\section{Keywords}

Masonry arch bridge; Dynamic analyses; Finite element model; Seismic response.

Received: 19 June 2018; Accepted: 07 July 2018

ISSN: 2630-5763 (online) @ 2018 Golden Light Publishing® All rights reserved.

\section{Introduction}

Masonry arch bridges are significant part of cultural heritage and some of them are located in important transportation ways. These bridges reflect history of human society and social culture. Historical masonry bridges usually consist of arch, spandrel wall, backfill and foundation. These structures are exposed to many environmental vibrations during their lifetime and they are damaged or destroyed by natural disasters such as earthquakes. However, earthquakes are not the only reasons for the historical structures to sustain injury or to collapse; such as loss in the strength of the construction materials, time-dependent deformations, excessive and irregular loading due to inconvenient use, support settlements, floods, fires, wars and vandalism [1]. Structural behavior must be known for the protection and restoration of historical masonry bridges. Arch is the important segment of masonry bridges and most possibly one of the oldest architectural forms used for bridge type structures [2]. There are various studies in the literature about structural behavior of historical structures. Toker and Unay [1] made masonry arch bridge prototype and they applied various loads to bridge to investigate mathematical modelling techniques.

Brencich and Sabia [3] studied The Tanaro bridge. They made various tests for identify the natural frequencies, mode shapes and brickwork damping then used that data for set up the FEM model. Milani and Lourenço [4] investigated nonlinear response of masonry bridges using 3D FEM numerical code. Gullu and Jaf [5] examined SSI (Soil structure interaction) effect in the bridge. They performed 3D nonlinear time history analysis

\footnotetext{
Corresponding author

E-mail: erkutsayin@gmail.com
} 
of the Mataraci bridge. Valente and Milani [6] investigated behavior of eight masonry towers under nonlinear dynamic and nonlinear static analyses. Altunışık et al. [7] evaluated the arch thickness effects on the structural behavior of masonry arch bridges under dead load and live load. They obtained that the arch thickness of the masonry bridge influence on the structural behavior. Olmos et al. [8] identified the dynamic properties of masonry arch bridges and develop the numerical model of these bridges. They applied an ambient vibration tests and measured the signals to identify the dynamic properties of the bridges. Sayın et al. [9] modelled the historical Uzunok bridge using 3D finite element method and they performed linear and nonlinear analyses. Karaton et al. [10] evaluated the nonlinear seismic responses of Malabadi bridge under different earthquake levels.

In this study, seismic response of a historical masonry arch bridge is investigated. The case study is the masonry arch bridge located in Maden, Elazığg, Turkey. For the seismic effect, 2003 Bingöl earthquake acceleration records are used. Three dimensional finite element model of the bridge is generated using ANSYS software and dynamic analysis are performed. Dynamic responses of the bridge such as principal stress, principal strain and displacements are analyzed.

\section{Historical masonry Dutpınar bridge}

Historical Dutpınar masonry arch bridge is located in Maden which is town of Elazig. The bridge is

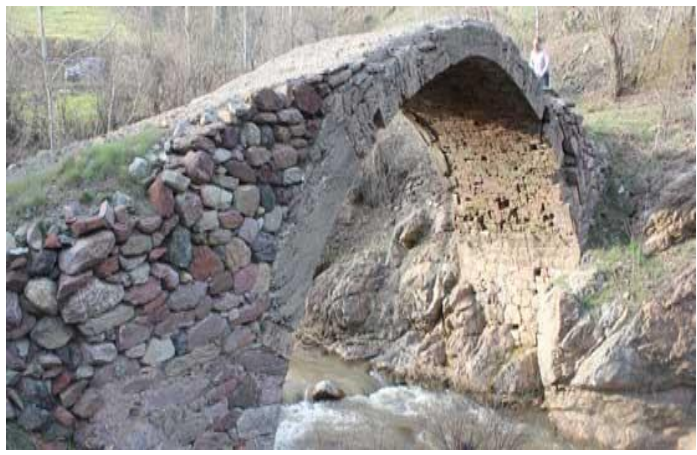

a) Before the restoration
$19.38 \mathrm{~m}$ long and $3.7 \mathrm{~m}$ wide. The thickness of spandrel walls and arch are $0.40 \mathrm{~m}$ and $0.55 \mathrm{~m}$, respectively. It has one arch and its span is $11.05 \mathrm{~m}$. The construction year of the bridge is not known exactly. The bridge had been repaired at various times. The last restoration was made by 8 th Regional Directorate of Highways at 2015 (Fig. 1). The geometrical properties of the Dutpinar Bridge are shown in Fig. 2.

\section{Numerical modeling of masonry structures}

Depending on the size of structural system and the level of accuracy, three different modeling techniques which called detailed micro modeling, simplified micro modeling and macro modeling are commonly used for numerical modelling of masonry structures [11]. In the detailed micro modelling, the material specifications of the masonry units and the mortar are evaluated separately. In the simplified micro-modelling technique, the masonry units are widened by as much as half of the mortar layer.

So, the mortar layer is neglected, and the masonry units are separated from one another through the interface lines. In the macro-modelling, the masonry accepts as a composite without making a distinction between unit and mortar. Because of its low computational effort, macro-modelling technique is the most common technique for analysis of large scale models and commonly used in the literature [12-15]. These modeling strategies are given in Fig. 3.

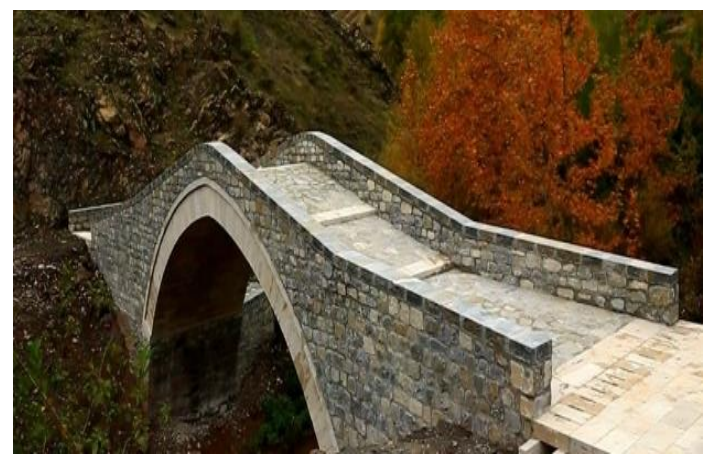

b) After the restoration

Fig. 1. View of the Dutpınar Bridge 


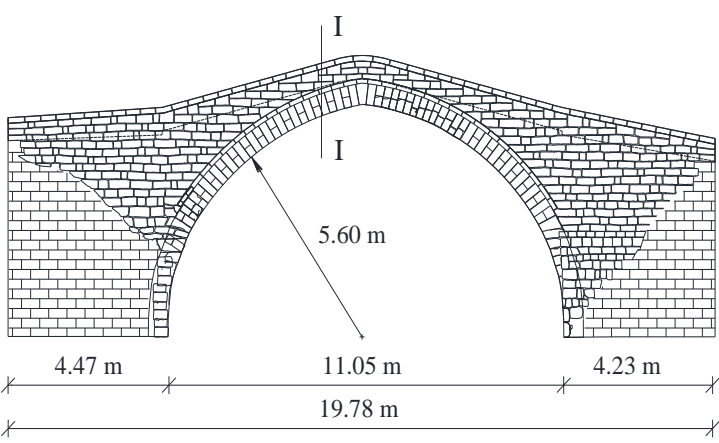

a) Plan view of the bridge

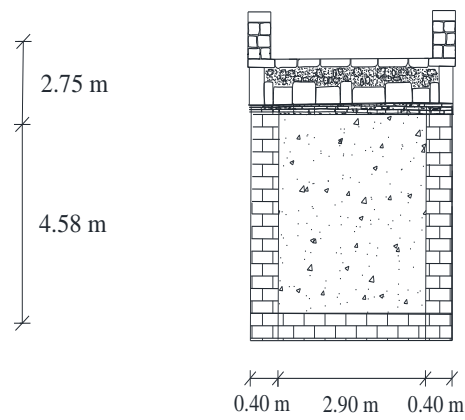

b) Section I-I

Fig. 2. Geometrical properties of Dutpınar Bridge

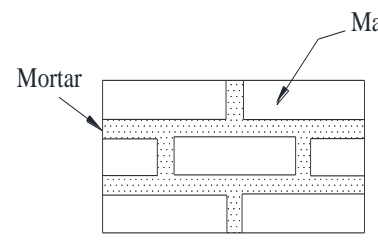

a) Detailed micro-modelling

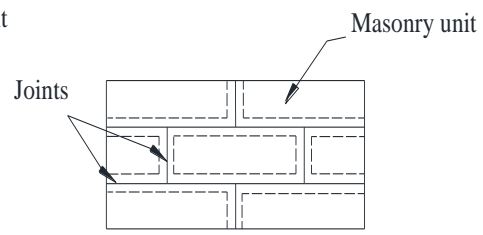

b) Simplified micro-modelling

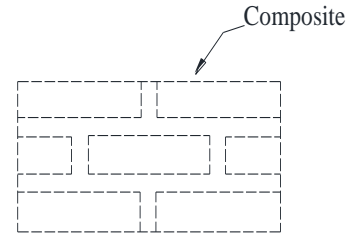

c) Macro-modelling

Fig. 3. Modelling approaches for masonry structures

Three dimensional model of the bridge is constituted using ANSYS finite element software with macro modelling approach. Finite element model of the bridge is generated using SOLID186 element. The element is defined by 20 nodes having three degrees of freedom per node: translations in the nodal $\mathrm{x}, \mathrm{y}$, and $\mathrm{z}$ directions [16]. The geometry of this element is presented in Fig. 4. Three dimensional finite element model of the bridge and selected nodal point (4970) is given in Fig. 5. This model consists of 12575 nodal points and 7901 solid elements.

Because the bridge is supported on the rock region, all degrees of freedom at the foundation of the bridge is assumed as fixed in the finite element model. It is difficult to decide the material properties of the historical structures. Because of difficulties, similar material properties in the literature are considered in this study [17]. The material properties of the bridge used in the analyses are given in Table 1.

\section{Numerical analyses}

In this study, the earthquake behavior of the masonry arch bridge is investigated. For this purpose, 2003 Bingöl earthquake acceleration record is used for the seismic effect (Fig. 6). To assess the real structural response of the bridge, East-West (E-W), Up-Down (U-D) and NorthSouth (N-S) component of the earthquake is applied simultaneously to the bridge at $\mathrm{x}, \mathrm{y}$ and $\mathrm{z}$ direction, respectively. 10 second acceleration record of the earthquake which is effective duration is taken into account in the analysis.
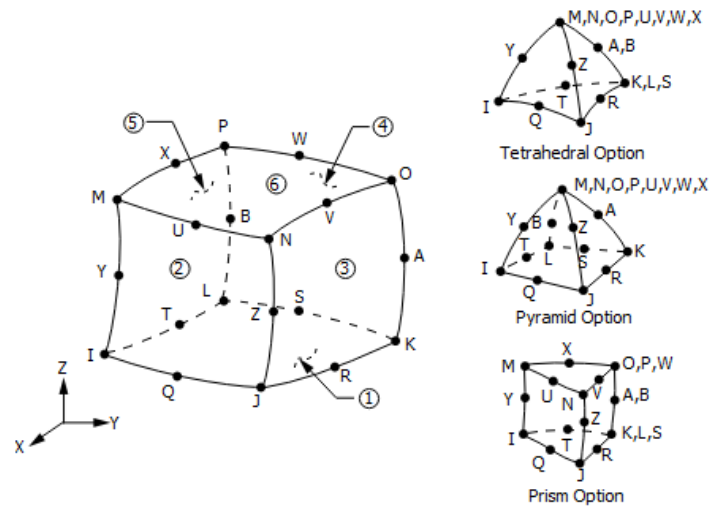

Fig. 4. Geometry of SOLID186 element [16] 


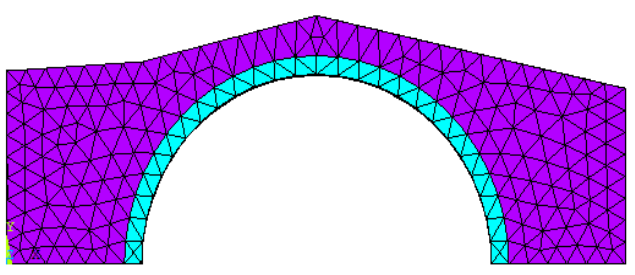

a) Front view

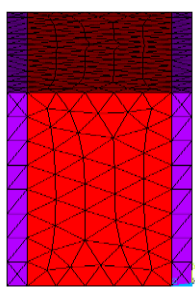

b) Side view

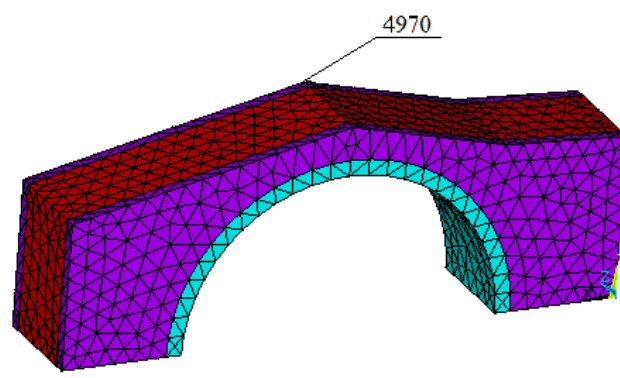

c) Isometric viev

Fig. 5. Three dimensional finite element model of Dutpınar bridge

Table 1. Material properties used in the analyses

\begin{tabular}{cccc}
\hline & Elasticity modulus $\left(\mathrm{N} / \mathrm{m}^{2}\right)$ & Density $\left(\mathrm{kg} / \mathrm{m}^{3}\right)$ & Poisson ratio \\
\cline { 2 - 4 } Arch & $2.8 \mathrm{E} 9$ & 2800 & 0.20 \\
Spandrel wall & $2.4 \mathrm{E} 9$ & 2400 & 0.20 \\
Infill material & $1.5 \mathrm{E} 9$ & 1500 & 0.23 \\
\hline
\end{tabular}

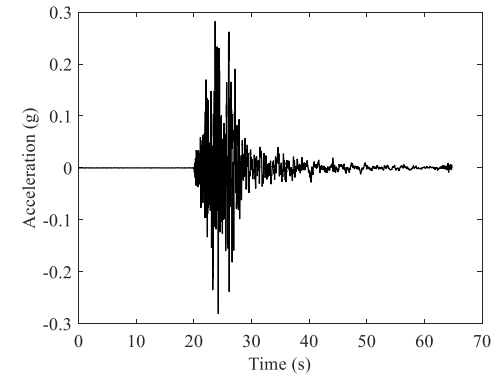

a) E-W component

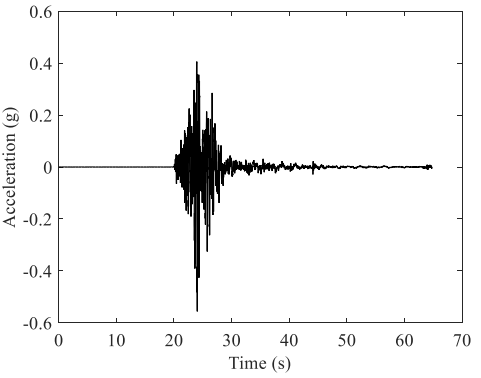

b) N-S component

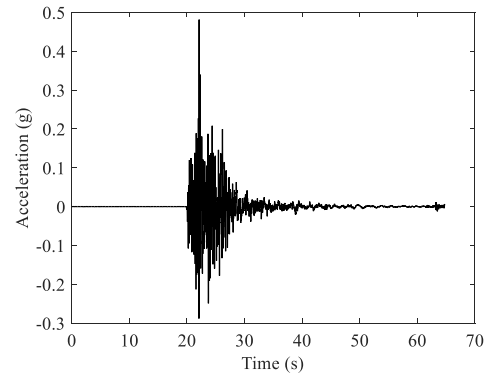

c) U-D component

Fig. 6. Acceleration records of Bingöl earthquake

Newmark method is used in the solution of the equation of motion. Integration time step is selected as $0.01 \mathrm{~s}$. The viscous damping in the bridge is considered as $5 \%$ in linear dynamic analysis as being proportional to the stiffness and mass matrices. Linear time history analysis is a step-bystep procedure of the dynamic response of the structure. The loading and the response histories are assessed at each time step. Solutions are obtained by using ANSYS finite element program. The first three mode shapes and natural frequencies of the bridge are given in Fig. 7. After the linear dynamic analysis, displacement contours of the bridge which are obtained in $\mathrm{x}, \mathrm{y}$ and $\mathrm{z}$ direction are presented in Fig. 8.

After the linear dynamic analysis, displacement contours of the bridge which are obtained in $\mathrm{x}, \mathrm{y}$ and $\mathrm{z}$ direction are presented in Fig. 8. It can be seen from the Fig. 8 that the displacements have an increasing trend from side abutments (spandrel walls) to the middle of the arch span. The displacements reach the absolute maximum values at the middle of the arch. 


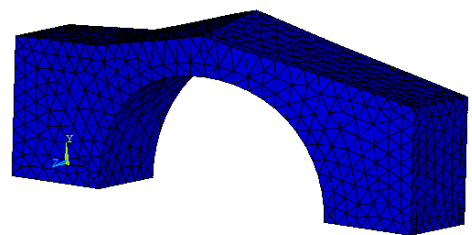

a) first mode $(\mathrm{f} 1=10.07 \mathrm{~Hz})$

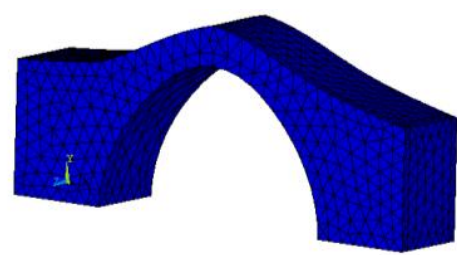

b) second mode $(\mathrm{f} 2=17.99 \mathrm{~Hz})$

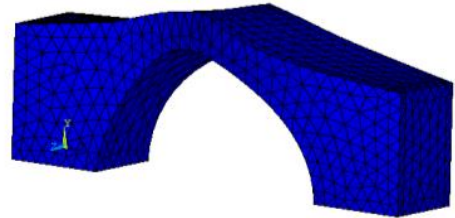

c) third mode $(\mathrm{f} 3=20.81 \mathrm{~Hz})$

Fig. 7. Natural frequencies and mode shapes of the bridge

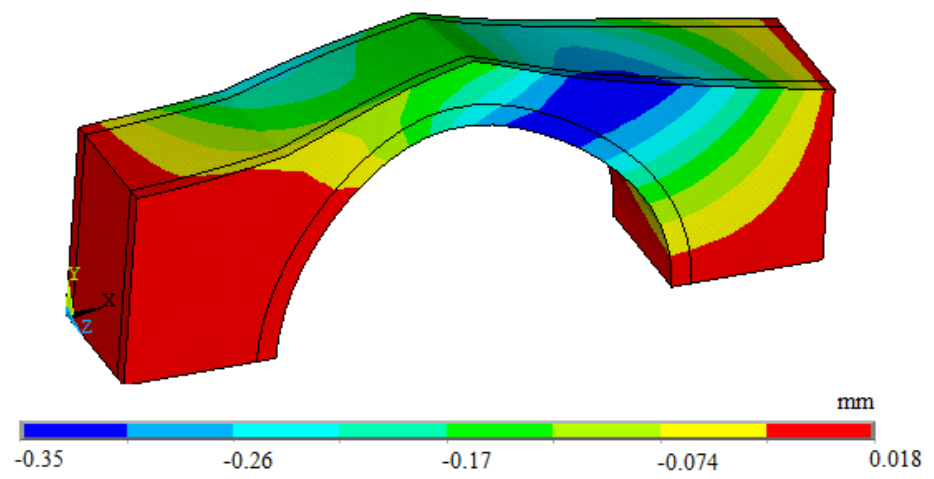

a) $x$ direction

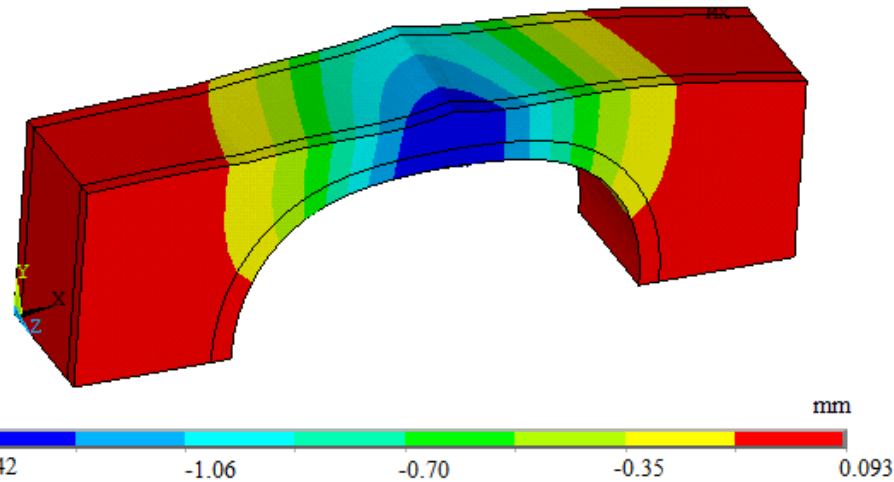

b) y direction

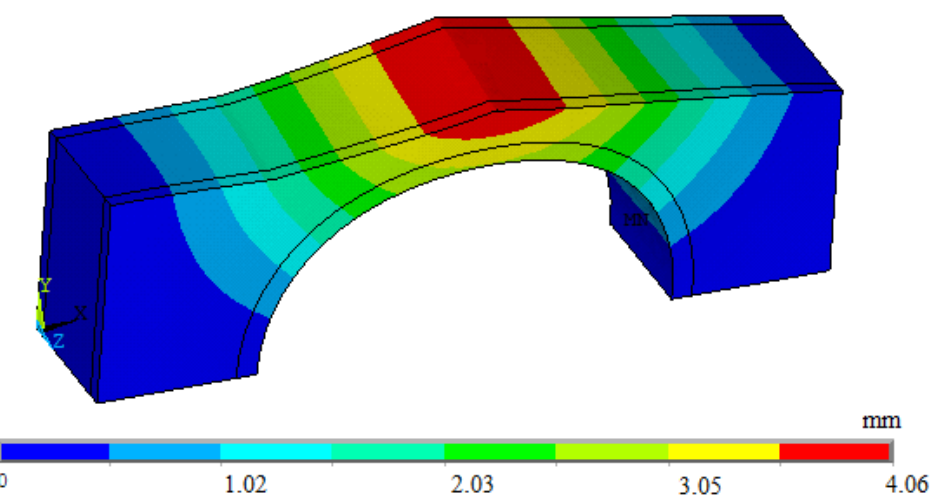

c) z direction

Fig. 8. Displacement contours of the bridge 
Also, time histories of the nodal point 4970 which is top of the bridge is presented in Fig. 9. Absolute maximum displacement of the nodal point 4970 is obtained as $0.13 \mathrm{~mm}, 1.39 \mathrm{~mm}$ and 4.06 $\mathrm{mm}$ in $\mathrm{x}, \mathrm{y}$ and $\mathrm{z}$ direction, respectively. These peak displacements are achieved as $4.21 \mathrm{~s}$., $2.77 \mathrm{~s}$. and $4.58 \mathrm{~s}$. in $\mathrm{x}, \mathrm{y}$ and $\mathrm{z}$ direction, respectively.

Maximum and minimum principal stress contours of the bridge are given in Fig. 10. It is seen from the Fig. 10 that maximum value of the tensile stresses occurred at upper part of the spandrel wall as $-1.25 \mathrm{MPa}$. Excluding this section, tensile stresses are reached maximum values as $-1.04 \mathrm{MPa}$ at right and left of the arch base. Also, there are some stress accumulations regions with $1.17 \mathrm{MPa}$ maximum stress value at right and left of the arch base and upper part of the spandrel walls. If the maximum and minimum stress obtained in the analyses exceed the tensile and compressive strength of the bridge material, potential damages

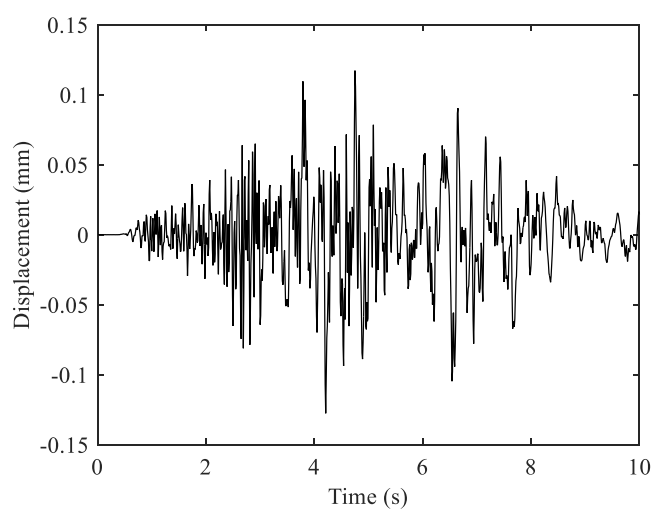

a) $\mathrm{x}$ direction (cracking and crushing) can occur initially at these regions.

The time histories of the maximum and minimum principal stresses of the bridge subjected to the 2003 Bingöl earthquake acceleration records are plotted in Fig. 11.

Maximum and minimum principal strain contours of the bridge are given in Fig. 12 and 13. It is seen from the Fig. 12-13 that maximum and minimum elastic strains are attained as 0.00046 and -0.00049 , respectively. Also, there are some strain accumulations regions with 0.00037 maximum strain value at the right and left of the arch base and upper part of the spandrel walls. Moreover, there are some strain accumulations regions with 0.00039 minimum strain value at the right and left of the arch base and upper part of the spandrel walls. The time histories of the maximum and minimum principal strain of the bridge are plotted in Fig. 14.

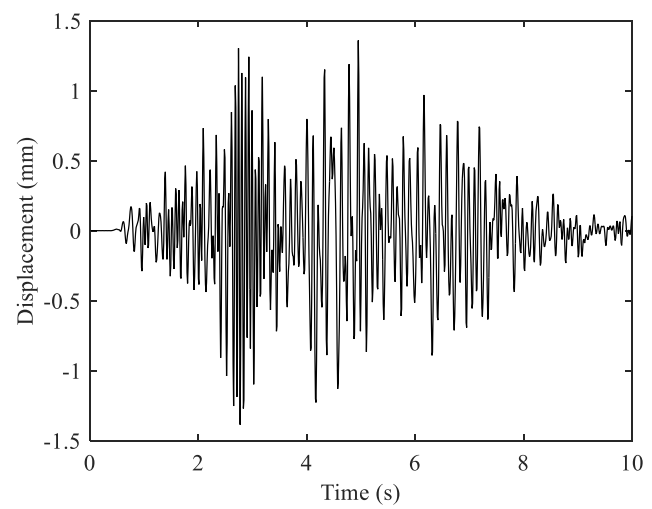

b) y direction

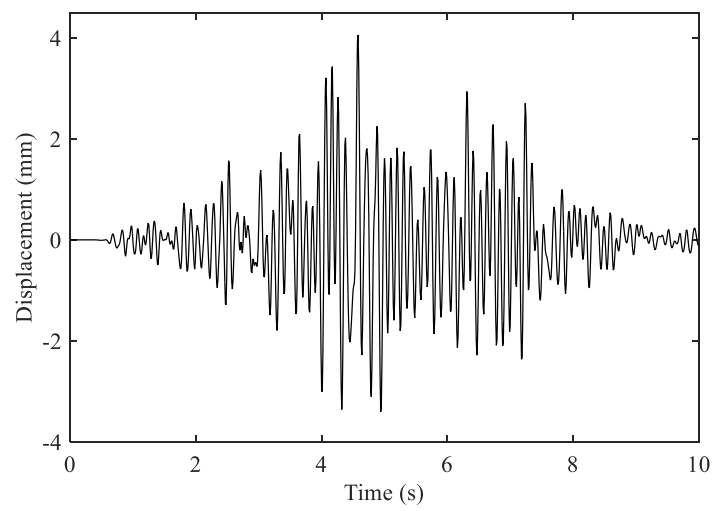

c) $\mathrm{z}$ direction

Fig. 9. Time histories of the nodal point 4970 


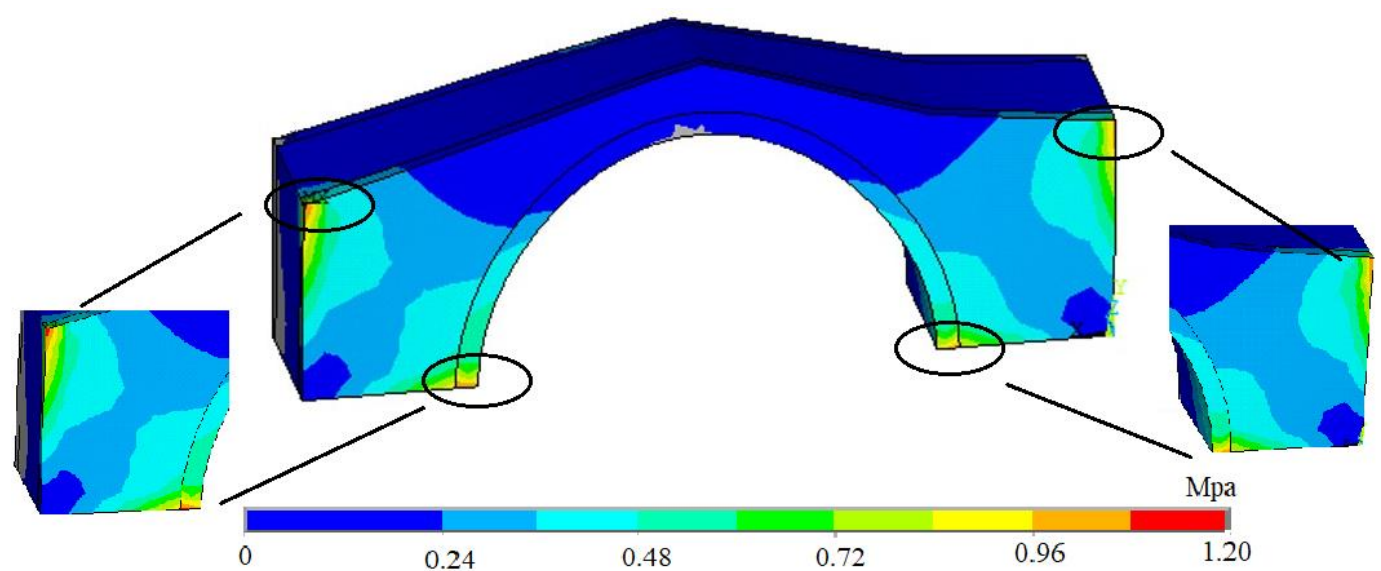

a) Maximum principal stresses

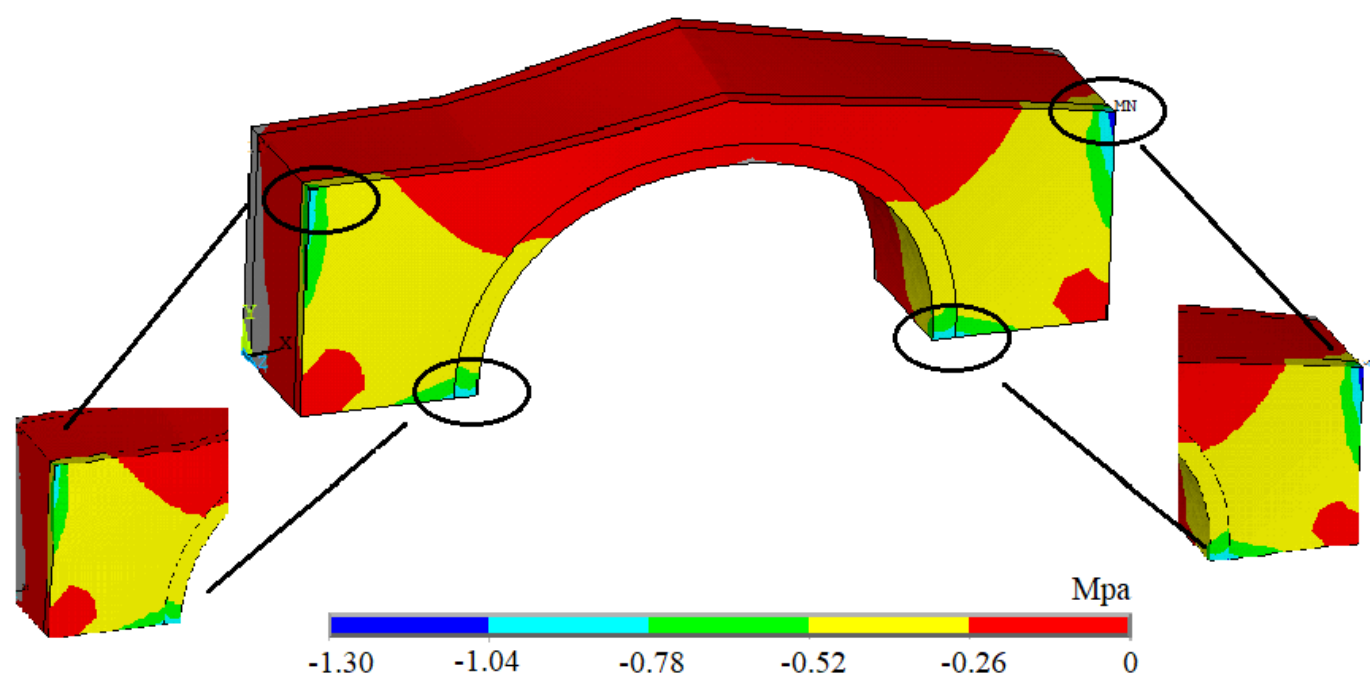

b) Minimum principal stresses

Fig. 10. Maximum and minimum principal stress contours of the bridge

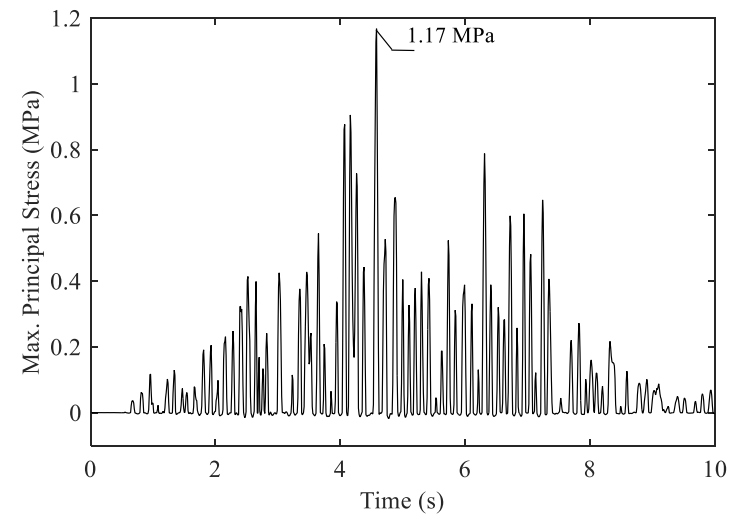

a) Time histories of maximum principal stress

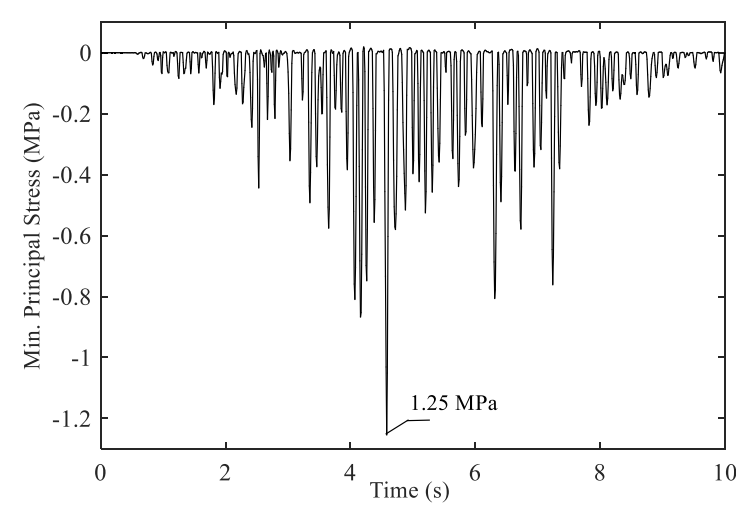

b) Time histories of minimum principal stress

Fig. 11. Time histories of maximum and minimum principal stress 


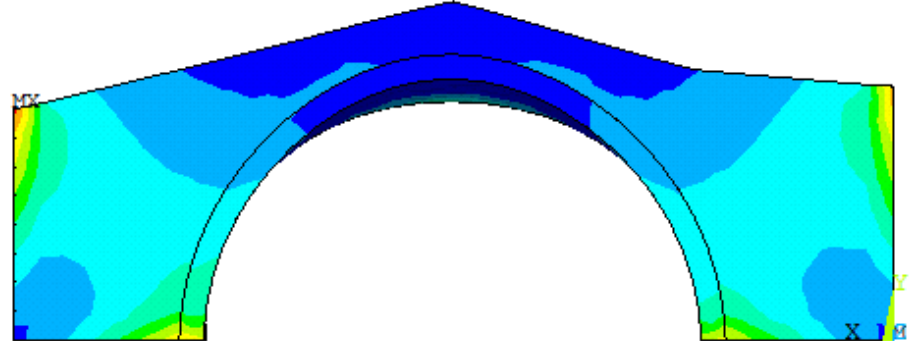

a) Front view

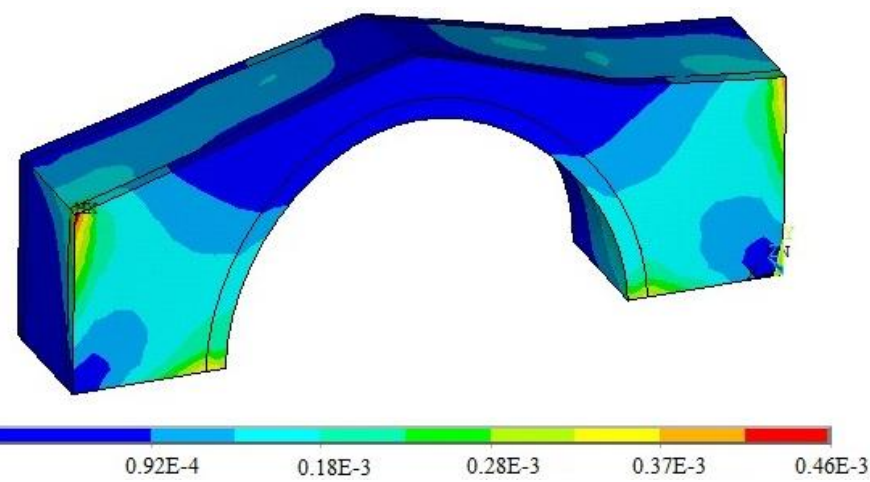

c) Isometric view

Fig. 12. Maximum principal strain contours of the bridge

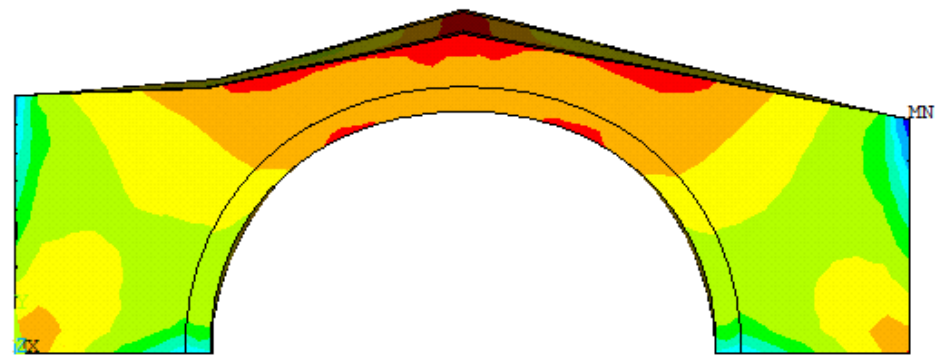

a) Front view

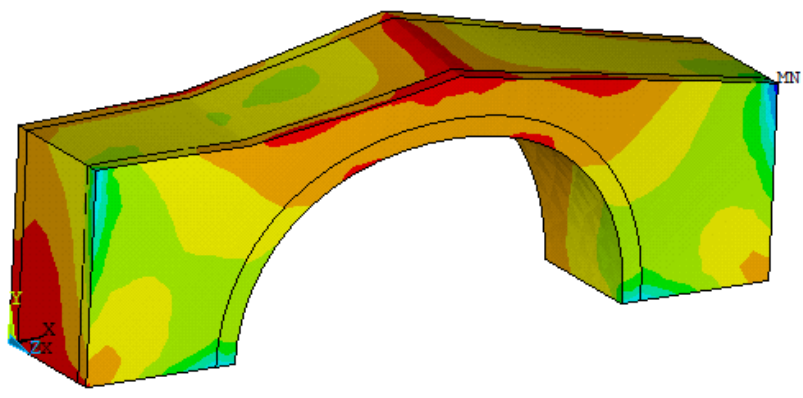

$-0.49 \mathrm{E}-3$

$-0.39 \mathrm{E}-3$

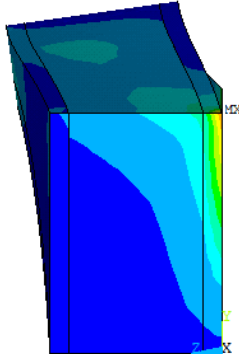

b) Side view 


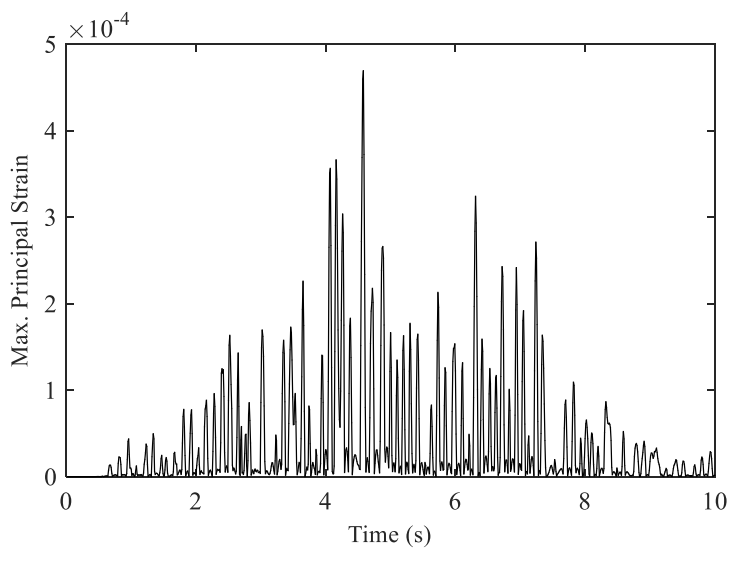

a) Time histories of maximum principal strain

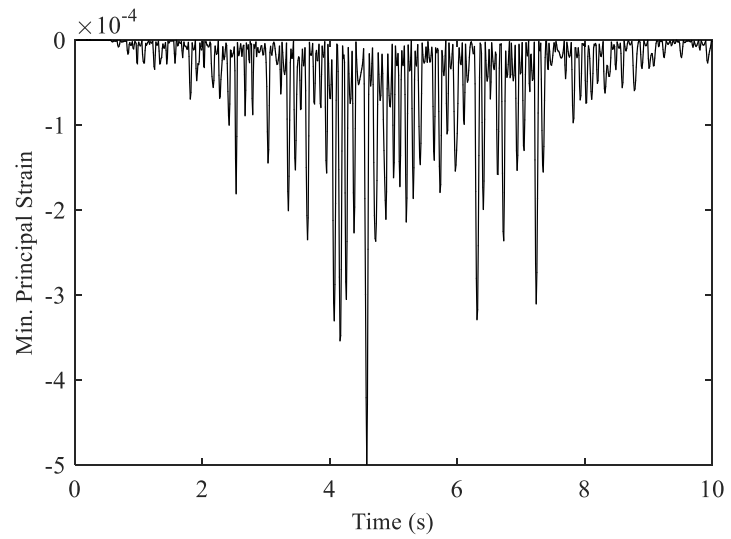

b) Time histories of minimum principal strain

Fig. 14. Time histories of maximum and minimum principal strain

\section{Conclusions}

Nowadays, protection and restoration of historical structures are very important subject. Therefore, the structural characteristics of these structures must be known. The aim of the study is to investigate seismic response of a historical masonry arch bridge using 2003 Bingöl earthquake acceleration records. Dutpinar masonry arch bridge located in Maden is selected as a case study. For this purpose, three dimensional finite element model of the bridge is generated with ANSYS software and linear dynamic analyses are performed. Stiffness and mass proportional viscous damping ratio is selected as \%5 in the analyses. All degrees of freedom at the base of the model are assumed as fixed. Displacement of the nodal point located at the top of the bridge is obtained in $\mathrm{x}, \mathrm{y}$ and $\mathrm{z}$ direction. Also, maximum and minimum principal stress and strains contours of the bridge are achieved. Linear dynamic analysis can be used to determine the potential locations of initial damages.

\section{References}

[1] Toker S, Ünay AI (2004) Mathematical modelling and finite element analysis of masonry arch bridges. G.U. Journal of Science 17(2): 129139.

[2] Bayraktar A, Altunışık AC, Birinci F, Sevim B, Turker $\mathrm{T}$ (2010) Finite-element analysis and vibration testing of a two-span masonry arch bridge. Journal of Performance of Constructed Facilities 24(1): 46-52.

[3] Brencich A, Sabia D (2008) Experimental identification of a multi-span masonry bridge: The Tanaro Bridge. Construction and Building Materials 22: 2087-2099.

[4] Milani G, Lourenço PB (2012) 3D non-linear behavior of masonry arch bridges. Computers \& Structures 110(111): 133-150.

[5] Güllü H, Jaf HS (2016) Full 3D nonlinear time history analysis of dynamic soil-structure interaction for a historical masonry arch bridge. Environmental Earth Sciences 75: 1421-1438.

[6] Valente M, Milani G (2016) Non-linear dynamic and static analyses on eight historical masonry towers in the north-east of Italy. Engineering Structures 114: 241-270.

[7] Altunışık AC, Kanbur B, Genç AF (2015) The effect of arch geometry on the structural behaviour of masonry bridges. Smart Struct. Syst. 16(6): 1069-1089.

[8] Olmos BA, Jara JM, Martínez G, López JI (2017) System identification of history Mexican masonry bridges. Procedia Engineering 199: 2220-2225.

[9] Sayın E, Calayır Y, Karaton M. Nonlinear seismic analysis of historical Uzunok bridge. Seventh National Conference on Earthquake Engineering, 30 May-3 June, 2011, Istanbul, Turkey.

[10] Karaton M, Aksoy S, Sayın E, Calayır Y (2017) Nonlinear seismic performance of a 12 th century historical masonry bridge under different 
earthquake levels. Engineering Failure Analysis 79: 408-421.

[11] Lourenço PB. Computational strategies for masonry structures, $\mathrm{PhD}$. Thesis, Delft Technical University of Technology, The Netherlands, 1996.

[12] Carpinteri A, Invernizzi S. Lacidogna G (2005) In situ damage assessment and nonlinear modelling of a historical masonry tower, Engineering Structures 27(3): 387-395.

[13] Pela L, Aprileb A, Benedettic A (2013) Comparison of seismic assessment procedures for masonry arch bridges. Construction and Building Materials 38: 381-394.
[14] Zampieri P, Zanini MA, Modena C (2015) Simplified seismic assessment of multi-span masonry arch bridges. Bulletin of Earthquake Engineering 13(9): 2629-2646.

[15] Sayın E (2016) Nonlinear seismic response of a masonry arch bridge. Earthquakes and Structures 10(2): 483-494.

[16] ANSYS, Finite Element Software, Swanson Analysis System. Inc., Houston, TX, USA, 2015.

[17] Frunzio G, Monaco M, Gesualdo A (2001) 3D F.E.M analysis of a Roman arch bridge. Historical Constructions, Eds., P.B. Lourenço, P. Roca, Guimarães 591-597. 